\title{
Screening for inter-hospital differences in cesarean section rates in low-risk deliveries using administrative data: An initiative to improve the quality of care
}

\author{
Willem Aelvoet*1,2,3, Francis Windey1, Geert Molenberghs ${ }^{4}$, \\ Hans Verstraelen ${ }^{5}$, Patrick Van Reempts ${ }^{6}$ and Jean-Michel Foidart ${ }^{7}$
}

\begin{abstract}
Address: ${ }^{1}$ Federal Service of Health, Food Chain Safety and Environment, Brussels, Belgium, ${ }^{2}$ Epidemiologie en Sociale Geneeskunde, Universiteit Antwerpen, Antwerp, Belgium, ${ }^{3}$ Faculteit Geneeskunde en Farmacie, Vrije Universiteit Brussels, Brussels, Belgium, ${ }^{4}$ Center for Statistics, Hasselt University, Diepenbeek, Belgium, 5 Department of Obstetrics \& Gynaecology, Ghent University, Ghent University Hospital, Ghent, Belgium, ${ }^{6}$ Department of Neonatology, Antwerp University Hospital, Antwerp, Belgium and ${ }^{7}$ Department of Obstetrics and Gynaecology, La Citadelle Hospital, University of Liège, Liège, Belgium
\end{abstract}

Email: Willem Aelvoet* - willem.aelvoet@ health.fgov.be; Francis Windey - francis.windey@health.fgov.be; Geert Molenberghs - Geert.Molenberghs@uhasselt.be; Hans Verstraelen - hans.verstraelen@Ugent.be; Patrick Van Reempts - Patrick.Van.Reempts@uza.be; Jean-Michel Foidart - jmfoidart@ulg.ac.be

* Corresponding author

Published: 4 January 2008

BMC Health Services Research 2008, 8:3 doi:10.1186/1472-6963-8-3

This article is available from: http://www.biomedcentral.com/1472-6963/8/3

(c) 2008 Aelvoet et al; licensee BioMed Central Ltd.

This is an Open Access article distributed under the terms of the Creative Commons Attribution License (http://creativecommons.org/licenses/by/2.0), which permits unrestricted use, distribution, and reproduction in any medium, provided the original work is properly cited.
Received: 29 March 2007

Accepted: 4 January 2008

\begin{abstract}
Background: Rising national cesarean section rates (CSRs) and unexplained inter-hospital differences in CSRs, led national and international bodies to select CSR as a quality indicator. Using hospital discharge abstracts, we aimed to document in Belgium (I) inter-hospital differences in CSRs among low risk deliveries, (2) a national upward CSR trend, (3) lack of better neonatal outcomes in hospitals with high CSRs, and (4) possible under-use of CS.

Methods: We defined a population of low risk deliveries (singleton, vertex, full-term, live born, <4500 g, >2499 g). Using multivariable logistic regression techniques, we provided degrees of evidence regarding the observed departure ([relative riskI]*100) of each hospital ( $N=107)$ from the national CSR and its trend. To determine a benchmark, we defined three CSR groups (high, average and low) and compared them regarding I minute Apgar scores and other neonatal endpoints. An anonymous feedback is provided to the hospitals, the College of Physicians (with voluntary disclosure of the outlying hospitals for quality improvement purposes) and to the policy makers.

Results: Compared with available information, the completeness and accuracy of the data, regarding the variables selected to determine our study population, showed adequate. Important inter-hospital differences were found. Departures ranged from $65 \%$ up to $+75 \%$, and 9 "high CSR" and I 3 "low CSR" outlying hospitals were identified. We observed a national increasing trend of I.019 (95\% Cl [I.015; I.022]) per semester, adjusted for age groups. In the "high CSR" group I minute Apgar scores < 4 were over-represented in the subgroup of vaginal deliveries, suggesting CSs not carried out for medical reasons. Under-use of CS was also observed. Given their questionable completeness, except Apgar scores, our neonatal results, showing a significant association of CS with adverse neonatal endpoints, are to be cautiously interpreted. Taking the available evidence into account, the "Average CSR" group seemed to be the best benchmark candidate.

Conclusion: Rather than firm statements about quality of care, our results are to be considered a useful screening. The interhospital differences in CSR, the national CS upward trend, the indications of over-use and under-use, the geographically different obstetric patterns and the admission day-related concentration of deliveries, whether or not by CS, may trigger initiatives aiming at improving quality of care.
\end{abstract}




\section{Background}

Over the past few decades, there has been a tremendous rise in the number of deliveries performed through cesarean section in most industrialized countries. While both longitudinal as well as cross-sectional variations in cesarean section rates would be expected to reflect primarily differences in obstetric complications, it is actually observed that wide differences occur between countries, regions or even hospitals within the same region with similar socio-economic profiles and patient characteristics $[1,2]$. The latter seems to suggest that CS is probably often performed for non-medical reasons leading to an overall overuse of this surgical obstetric intervention. Indeed, it has been acknowledged that elective primary and repeat CS contributed heavily to the cesarean rise $[3,4]$. In the US for instance, the overall CSR increased by some 14\% from 1998 to 2001 as a result of a 13\% increase in medically indicated primary CS, yet a 53\% increase in the rate of elective primary CS [3]. Similarly, vaginal birth after cesarean delivery (VBAC) rates decreased by $27 \%$ between 1996 and 2000, because of the rare but potentially catastrophic risks and medical litigation $[4,5]$.

Meikl et al[3] describe elective caesarean as:" Elective cesarean deliveries can include medically and obstetrically indicated procedures that generally occur before labor. Elective cesarean deliveries can also include procedures for which there is no clear medical or obstetric indication." In the framework of a quality indicator, which aims at to monitor and reduce the caesarean rate [1], both aspects of their description are to be considered.

When comparing the CSRs between hospitals it is then important to exclude from the comparison medically and obstetrically indicated cesarean sections[4] and only to include procedures for which there is no clear medical or obstetric indication. We will call the latter type of cesarean sections: "elective cesareans" in the remainder of this manuscript. We also consider a repeat cesarean as medically and obstetrically indicated and therefore to be excluded from the comparison.

It is difficult to strike a balance between elective CS, which we understand as a procedure that occurred before labor, and vaginal delivery in the absence of randomized controlled trials [2].

Yet, it appears to be well established that in case of uncomplicated pregnancy, cesarean section exposes the parturient to inadvertent risks without offering a defined benefit [6]. The increase in the incidence of placenta accreta (from 1/30,000 pregnancies in the 1950 s to $1 / 533$ nowadays) and its dramatic consequences mainly have been ascribed to the increased CSR [7]. As a matter of fact, several studies revealed that the overall increase in cesar- ean rates has not led to a general decrease in perinatal mortality or birth asphyxia [8,9] and some countries with rather low CSRs experience low perinatal mortality rates, suggesting that good perinatal outcome does not necessarily equate high CSRs [10]. Nonetheless some authors argue that elective CS is as safe as or even safer than vaginal delivery [11].

Financial reasons and relative easiness may play a part in the mode of delivery decision-making, and when analyzing data on the subject, it can be difficult to distinguish between patient's or physician's choice $[2,6,12]$. Informed consent, maternal preferences, maternal autonomy, and the physician factor may play a role as well. Finally, decreasing parity (most women have less than two pregnancies) and medico-legal considerations can also contribute to the decision process $[6,11,13]$.

Though it proves difficult to pinpoint the adequacy of obstetric care at the patient level. There is a defined need to monitor cesarean rates at the national, regional, and hospital levels to detect both over- and under-use[10] of $\mathrm{CS}$. The use of CSR as a quality indicator in some countries, the contribution of informed consent and societal considerations to the decision-making process as well as clinical and epidemiological considerations, and the knowledge that CRS can be safely reduced by targeted interventions, led us to use CSR as a quality indicator of health care $[1,14,15]$. As CSR is a process indicator rather than an outcome itself, we also tried to demonstrate that CSR affects neonatal outcomes [16].

In the present population-based study, we used hospital discharge abstracts to select a predefined population of low risk deliveries and we subsequently aimed to explore the presence of both statistically and clinically significant inter-hospital differences in hospital-specific CSRs. We further hypothesized that hospitals with a high CSR would not experience better neonatal outcomes. Possible under-use was also to be evaluated.

\section{Methods \\ Data sources}

Since October 1990 all Belgian hospitals are subjected to compulsory registration with the health authorities of each admission through a standard form containing a defined set of clinical data including ICD-coded diagnoses and procedures. These discharge abstracts are termed Minimal Clinical Data (MCD) and contain patient data (among which year of birth, gender, residence, and anonymous hospital and patient identifiers), stay data (among which year and month of admission and discharge, length of stay, transfer to another hospital with specification of the type of hospital) and an unlimited number of diagnoses and procedures. This information is transmitted to 
the authorities for compilation and processing. Hospitals are further characterized according to teaching status (teaching or non-teaching), ownership (private or public) and the presence or absence of intensive maternal or neonatal care or otherwise. Hence, the MCD database covers all stays in Belgian hospitals, including those of non-residents. Because of the absence of a unique patient identifier, it is not possible, in case of a neonatal transfer, to get matching maternal and infant data in the "intake" hospital. Conversely all these data are available in the "discharge" facility's data.

In order to assess possible incompleteness and/or inaccuracy of the data - which are well-known drawbacks of administrative data [17] - we compared the MCD data with various partially overlapping registries, in particular data extracted from (1) the National Institute of Statistics (NIS), which are confined to residents, (2) the Center for the Study of Perinatal Epidemiology (SPE), a populationbased perinatal data registry, confined to Flanders, the Northern half of the country, and (3) published data from the Office de la Naissance et de l'Enfance (ONE), providing perinatal data regarding the Southern part of the country [18].

In the SPE registry all perinatal deaths and live births occurring in the participating Flemish obstetrical units (residents and non-residents) are recorded, as well as a proportion of the home deliveries (about $1 \%$ of all deliveries). The data are collected on a routine and continuous basis and are submitted to an organized system of quality insurance [19]. The NIS data may be considered almost complete and of good quality as these data originate from the register of births, deaths and marriages, frequently used for administrative purposes. The ONE data regarding Apgar score and birth weight may be considered complete [20].

\section{Definition of the study population}

A valid inter-hospital comparison of CSRs requires an adjustment for case mix. Alternatively, a population with a presumably equal risk of obstetric intervention may be defined for further analysis. Accordingly, we aimed to define a subgroup of parturients which is considered at low-risk of having a medically indicated CS [21], by excluding any patient that could have been considered at increased risk for a CS according to the US Agency for Healthcare Research and Quality (AHRQ) [1].

We excluded all deliveries involving abnormal presentation (including breech) or breech procedure, preterm gestation ( $<37$ weeks), fetal death, and multiple gestations according to the criteria of the US AHRQ. On request of the Belgian College of Physicians we further excluded all cases of full-term small-for-gestational age (defined as newborns born after 36 completed weeks of gestation with a birth weight of less than $2500 \mathrm{~g}$ ) or macrosomia (defined as by birth weight of at least $4500 \mathrm{~g}$ ).

All above-mentioned maternal characteristics were identified by Diagnosis Related Group (DRG) or by diagnosis and procedure codes of the International Classification of Diseases $9^{\text {th }}$ Revision Clinical Modification (ICD-9-CM). (Precise ICD-9-CM diagnosis and procedure codes can be found on the AHRQ's website [3].

The sampling frame consisted of the 455,933 deliveries, involving live born singletons in vertex presentation that were registered from 2001 to 2004. Thereof 86,310 $(18.96 \%)$ were classified as cesarean deliveries. By applying the aforementioned criteria the final data set, the study population, comprised 381,989 deliveries of which 49,578 $(12.98 \%)$ by cesarean section. Out of the 73,944 deliveries, not meeting these criteria, $36,732(49,68 \%)$ were cesarean deliveries, the comparison population.

\section{Analysis}

Our aim was to identify, on the one hand, hospitals, with higher quality of obstetric care for benchmark and exemplary function purposes, and, on the other hand, hospitals with lower quality of care in order to help them improve their processes.

To assess hospital-specific rates of CS relative to the overall CS rate two analyses were carried out: a cross-sectional one focusing on the CSRs for the entire time span of the study (we call it the period) and a longitudinal one (we call it the trend) focusing on the per-semester evolution of the CSRs. In the latter analysis the unit of time used is the semester, the first semester comprising the first six months of the calendar year.

It has been suggested that in analyses, founded on administrative databases, confounding cannot be ruled out as an explanation of rather small, yet statistically significant effect sizes, such as a relative risk (RR) of 0.75 [22]. Therefore we defined a zone of non-interpretation, where the CS rate or trend of a hospital, compared with the national ones, should not be described as being "higher" or "lower". To determine the boundaries of this zone we firstly computed per hospital the relative risk (RR) of a hospital of having a higher/lower CS rate or trend than the national the national ones. We then calculated a departure D (expressed in \%): with the formula D = (RR-1) $\times$ 100 . Subsequently we defined the lower boundary as corresponding to a departure of minus 25 - which is equivalent to the afore-mentioned RR of 0.75 - and the upper boundary as a departure of plus 35, the lower boundary's approximate, statistical counterpart. 
In the absence of any references regarding the significance of departures from the CS trend and by assuming that data quality has remained constant over time, a similar zone of non-interpretation was defined to allow for a comparison in the evolution over time in the hospital-specific CS rates by which we arbitrarily allowed for a -5 to +5 departure from the national trend. In the other cases, characterized by important departures, the results of the analysis were interpreted according to the degree of statistical evidence. We labeled this evidence 1) "strong" if the probability of finding a departure, as important or bigger than that of the hospital under consideration, is smaller than or equal to $0.05 /$ number of hospitals to be compared (the socalled Bonferroni correction for multiple comparisons[23]); 2) "moderate" if that probability is smaller than or equal to 0.05 but greater than $0.05 /$ number of hospitals to be compared; 3 ) "weak" otherwise.

\section{Study goals}

The results of the analysis had to serve three purposes: to deliver (1) a feedback to the hospitals so they can improve care processes, (2) a feedback to the Belgian College of Physicians that will enable them to support hospitals identified with higher or lower quality, and (3) a feedback to health authorities as a useful tool for policy making.

The feedback to the hospitals consists mainly of a graphical display of the "departure" of all of the hospitals from the national rate/trend, of an anonymous and tabular representation of these departures as well as of an indication of the level of statistical evidence. An aid in the interpretation, combining the information of both the period and trend analyses, is provided alongside. Its decision tree is given in the Annex of the Supplementary materials (see Additional file 1).

In the feedback to the Belgian College of Physicians we present an average and two outlying categories of hospitals. A first, outlying category, the 'high CSR' group, consists of those hospitals with a departure of $>+35$ and statistically significant (Bonferroni-corrected). A second, outlying category, the 'low CSR' group, consists of those hospitals with a departure of $<-25$ and statistically significant (Bonferroni-corrected). The other hospitals are grouped into the 'average CSR' group. The decision tree is identical to that for the hospitals, except that hospitals recommended for an external audit are now divided in "high CSR" and "low CSR" groups and that the other hospitals are regrouped in an "average CSR" group.

\section{Neonatal endpoints}

As the optimal CSR is unknown, we compared the three CSR groups with respect to a number of selected neonatal endpoints like respiratory distress syndrome (RDS), meconium aspiration syndrome (MAS) and transient tachypnea of newborn (TTN), the main causes of neonatal morbidity [24,25]. We selected 1-minute and 5-minute Apgar scores [26]; RDS, MAS, TTN (ICD-9-CM codes 769, 770.1 and 770.6); need of respiration sustaining treatments; and admission into a specialized neonatal service as neonatal endpoints. Notice that in our view 1-minute Apgar scores, essentially indicating fetal distress, are rather used as a process, reflecting the degree of accordance of the obstetrical care to fetal status, than as an outcome indicator. The 5-minute Apgar scores would allow the identification of cases vaginally delivered that might have benefited of a CS.

In order to reduce inter-observer variability and according to the literature we regrouped the Apgar scores into three categories: "Apgar 0-3," "Apgar 4-6," and "Apgar > 6" $[27,28]$. The completeness of the data regarding Apgar scores may be more secure than that of the other neonatal endpoints since they are recorded by means of explicitly to-be-filled-out items whereas the others are open-question-like observations a hospital may or may not register.

To determine the possible influence of major congenital anomalies on the perinatal endpoints (see Additional file 2 ), we planned to twice carry out our analyses: once including and once excluding the cases of congenital anomalies [29].

\section{Statistical methods}

For our analyses we used so-called fixed effects models, because we focused on the whole of the Belgian hospitals and aimed at the identification of outlying hospitals, i.e. characterized by an important and statistically significant, Bonferroni-corrected [23] departure from the national CSR or CSR evolution over time. Given we cover the short time span of eight semesters, we only fitted models with a linear time trend, which for convenience we called "trend."

Hierarchical models, usually taking the form of so-called random-effects models, would have been an alternative. However, these models are not conceived to identify outliers. Further, the theory dealing with outliers still has to be developed for linear mixed models and it is impossible to identify outliers in non-linear mixed models [30,31]. Finally, in the random-effects models the hospitals in the set of data are considered a random sample from the larger population of all hospitals, contrary to the facts in our study.

Logistic regression [32] was performed to compare each individual hospital with all Belgian hospitals and to determine both a practically relevant and statistical significant departure from the national rate/trend. By incorporating an interaction term in the logistic regression between a 
linear time trend, expressed in semesters, and individual hospitals, those hospitals with an abnormal evolution in time were identified. Precisely, we compared the slope of each hospital's time trend with that of the national trend using linear contrasts.

In case of common outcomes ( $>10 \%)$, or if the odds ratio is greater than 2.5 or less than 0.5 , the estimation of the relative risk by the odds ratios, provided by the logistic regression, may become heavily biased. To reduce this bias we used the approximation of the RR by Zhang[33], which has been used to compute the afore-mentioned departure. The relation between $R_{Z}$ and the odds ratio is given by $R R_{Z}=O R /\left(\left(1-P_{0}\right)+\left(P_{0} * O R\right)\right.$, where $P_{0}$ indicates the incidence of the outcome of interest in the nonexposed group [33].

In the main analysis, adjustment was made for age of the mother and per-semester evolution of the CSRs. In a secondary analysis, type of hospital (private versus public, teaching versus non-teaching), gestational age, admission day and residence of the mother were considered determinants, susceptible both to influence a hospitals' CSR and to be modified by quality-directed initiatives.

To account for correlation within the data, rescaling techniques were used [34]. To study a possible national upward trend we used so-called Generalized Estimating Equations (GEE), a refinement of logistic regression that corrects for correlation within the data [31].

The neonatal endpoints were analyzed by multivariable logistic regression as well. As the Apgar categories constitute a multinomial endpoint, we intended to fit a proportional odds logistic model, provided the assumption of a constant odds ratio was met [35]. Otherwise, a generalized logit analysis was to be conducted [35].

Independence of two variables forming a contingency table and proportions were analyzed by means of chisquare tests. Cochran-Armitage trend tests were used where appropriate.

These statistical analyses were performed using SAS version 8.1, SAS Institute Inc., SAS Campus Drive, Cary, North Carolina 27513, US.

The study being (1) of a retrospective, non-interventional type and (2) anonymous with respect to both hospitals and patients, no approval by an ethics committee is required in Belgium.

\section{Results \\ Completeness and accuracy of the data}

According to residence of the mother, the MCD data showed very similar to those of the NIS, indicating their high degree of completeness regarding the number of live births (Table 1, section 1). As to the neonatal characteristics we observed an acceptable agreement between MCD and SPE regarding multiple gestation, gestational age, cesarean delivery, presentation, weight at birth, gender and Apgar scores (Table 1, section 2). However, regarding hypertension, diabetes, labor induction, epidural anesthesia, and history of a previous cesarean delivery, we found important disagreements. For the years 2001 and 2003 (see Additional file 3) almost identical figures were observed. The comparison of the MCD data with those of the ONE (data not shown) showed a good agreement with respect to birth weight and Apgar scores as well.

\section{Low risk pregnancies}

Comparing the study population (381,988 deliveries from which $12.98 \% \mathrm{CS}$ ) with the comparison population $(73,944$ deliveries of live born singletons (in vertex position) from which $49.68 \% \mathrm{CS}$ ), we found in the latter population a relative risk of being delivered by CS of 3.83, $95 \%$ CI $(3.79 ; 3.87)$. Applying to our source population the basic triad of "mothers with singleton, full-term (37 weeks and more) births involving a vertex presentation", recently used to describe maternal risk profiles[21], we would have had 395,021 low risk deliveries, giving rise to $52,611 \mathrm{CS}$ and to a relative risk of $1.12,95 \%$ CI (1.10; $1.13)$.

\section{Characteristics of the study population and mode of delivery. Belgium 200I-2004}

In the univariate analyses (see Additional file 4) several determinants of the CS rate were identified with relevance for the final analysis (Table 2). Increasing maternal age was associated with increasing CSRs (Cochran-Armitage: $\mathrm{p}<0.01)$. We further found that the CSRs were not homogeneously distributed across birth weight and gestational age groups (Chi-square: $\mathrm{p}<0.01$ ), and in particular that a GA of $>36$ and $<39$ weeks was associated with the highest gestational age-specific cesarean risk as was the birth weight category of 4000-4499 g. The CSR tended to be significantly higher for boys as compared to girls (OR: $1.14 ; 95 \%$ CI $[1.12 ; 1.16])$ as well. We also established an increasing CSR trend and an inverse correlation between the CS rate and the 1 ' and 5' Apgar scores (Cochran-Armitage trend: $\mathrm{p}<0.01)$. The respiratory syndromes were all significantly associated with the CSR: RDS, wet lung, and MAS had odds ratios of respectively: $3.07,95 \%$ CI $(2.76$; $3.44) ; 3.24,95 \%$ CI $(2.93 ; 3.59)$ and $1.60,95 \%$ CI $(1.45$; 1.77). Similarly, neonatal interventions such as respiratory support and admission to a specialized neonatal service were significantly associated with cesarean rates 
Table I: Completeness and accuracy of the data (in \%): comparison between MCD versus NIS, and between MCD versus SPE

\begin{tabular}{|c|c|c|c|c|}
\hline \multicolumn{5}{|c|}{ I) Comparison between $\mathrm{MCD}^{*}$ and $\mathrm{NIS}^{\circ}$ : number and distribution of live born infants, according to residence } \\
\hline \multirow[b]{2}{*}{ Residence } & \multicolumn{2}{|c|}{2002} & \multicolumn{2}{|c|}{2004} \\
\hline & MCD & NIS & MCD & NIS \\
\hline Belgium & $(\mathrm{N}=111,609)$ & $(\mathrm{N}=111,225)$ & $(\mathrm{N}=116,142)$ & $(N=115,618)$ \\
\hline Flanders & 53.1 & 53.7 & 53.0 & 53.9 \\
\hline Wallonia & 33.2 & 33.8 & 32.4 & 32.9 \\
\hline Brussels & 13.1 & 12.5 & 13.8 & 13.1 \\
\hline Abroad & 0.6 & - & 0.8 & - \\
\hline
\end{tabular}

2) Comparison between MCD and $S P E^{+}$: perinatal characteristics

\begin{tabular}{|c|c|c|c|c|}
\hline \multirow{3}{*}{ Deliveries } & \multicolumn{2}{|c|}{2002} & \multicolumn{2}{|c|}{2004} \\
\hline & MCD & NIS & MCD & NIS \\
\hline & $(N=58,194)$ & $(N=58,84 I)$ & $(N=59,126)$ & $(N=61,647)$ \\
\hline \multicolumn{5}{|l|}{ Multiple gestation } \\
\hline twins & 2.3 & 2.0 & 2.0 & 1.6 \\
\hline triplets & 0.1 & 0.0 & 0.1 & 0.0 \\
\hline Hypertension & 5.5 & 4.9 & 5.8 & 4.8 \\
\hline Diabetes & 1.6 & 1.2 & 2.1 & 1.4 \\
\hline \multicolumn{5}{|l|}{ Gestational age } \\
\hline 20-3I weeks & 1.0 & 1.0 & I.I & I.I \\
\hline 32-36 weeks & 6.1 & 6.3 & 6.4 & 6.5 \\
\hline$>=37$ weeks & 92.9 & 92.7 & 92.8 & 92.5 \\
\hline Labor induction & 19.4 & 30.1 & 17.7 & 27.6 \\
\hline Epidural anesthesia & 48.3 & 63.2 & 51.3 & 61.6 \\
\hline Cesarean delivery & 18.1 & 17.7 & 18.5 & 18.3 \\
\hline Previous cesarean & 4.6 & 7.6 & 5.7 & 8.2 \\
\hline \multirow[t]{2}{*}{ Births } & MCD & NIS & MCD & NIS \\
\hline & $(N=58,529)$ & $(N=60,048)$ & $(N=59,110)$ & $(N=62,657)$ \\
\hline \multicolumn{5}{|l|}{ Presentation } \\
\hline breech & 4.5 & 5.4 & 4.5 & 5.2 \\
\hline transverse & 0.5 & 0.6 & 0.4 & 0.5 \\
\hline \multicolumn{5}{|l|}{ Type of birth } \\
\hline spontaneous & 72.5 & 69.9 & 71.3 & 70.2 \\
\hline vacuum & 8.5 & 10.3 & 9.1 & 9.7 \\
\hline forceps & 0.6 & I.I & 0.5 & 0.9 \\
\hline cesarean & 17.9 & 18.3 & 18.2 & 18.9 \\
\hline vaginal breech & 0.5 & 0.4 & 0.4 & 0.3 \\
\hline \multicolumn{5}{|l|}{ Weight at birth } \\
\hline$<1500 \mathrm{~g}$ & 0.8 & 1.2 & 0.8 & I.I \\
\hline $1500-2499 \mathrm{~g}$ & 5.6 & 6.2 & 5.4 & 5.8 \\
\hline$>=2500 \mathrm{~g}$ & 93.3 & 92.7 & 93.7 & 93.1 \\
\hline \multicolumn{5}{|l|}{ Gender } \\
\hline male & 51.4 & 51.4 & 51.4 & 51.4 \\
\hline female & 48.6 & 48.6 & 48.6 & 48.6 \\
\hline Congenital anomalies & 3.0 & 1.8 & 3.1 & 1.6 \\
\hline Admission into specialized unit & 17.9 & 17.9 & 17.9 & 17.8 \\
\hline
\end{tabular}

Sources

*MCD: Minimal Clinical Data

${ }^{\circ}$ NIS: National Institute of Statistics

+SPE: Studiecentrum Perinatale Epidemiologie

(OR2.66, 95\% CI $(2.47 ; 2.87)$ and $1.27,95 \%$ CI $(1.24$; 1.30)). Finally, congenital anomalies proved another determinant of the CSR (OR 1.35, 95\% CI $(1.45 ; 1.77)$.
With regard to health services characteristics, interestingly we documented a considerably strong and statistically significant (Chi-square: $\mathrm{p}<0.0001$ ) association between day 
Table 2: Study population: characteristics and mode of delivery. Belgium 200 I-2004.

\begin{tabular}{|c|c|c|c|c|c|c|c|}
\hline & CS & $\%$ & Total & & CS & $\%$ & Total \\
\hline $\begin{array}{l}\text { I) Maternal } \\
\text { Age classes }\end{array}$ & & & & $\begin{array}{l}\text { 2) Neonatal } \\
\text { Gender }\end{array}$ & & & \\
\hline$<20$ years & 765 & 9.40 & 8,140 & Boys & 26,862 & 13.69 & $|96,19|$ \\
\hline $20-24$ years & 5,910 & 10.37 & 57,010 & Girls & 22,713 & 12.23 & 185,755 \\
\hline $25-29$ years & 15,987 & 11.92 & $|34,07|$ & Undetermined & 3 & & 23 \\
\hline $30-34$ years & 17,342 & 13.75 & 126,098 & Birth weight & & & \\
\hline $35-39$ years & 7,746 & 16.27 & 47,613 & $2500-2999 \mathrm{~g}$ & 9,444 & 13.78 & 68,511 \\
\hline 40 years + & 1,828 & 20.18 & 9,057 & $3000-3499 \mathrm{~g}$ & 20,431 & 12.18 & 167,699 \\
\hline Admission Day & & & & $3500-3999 \mathrm{~g}$ & 15,119 & 12.89 & 117,250 \\
\hline Monday & 9,560 & 14.84 & 64,422 & $4000-4499 \mathrm{~g}$ & 4,584 & 16.07 & 28,529 \\
\hline Tuesday & 8,827 & 13.80 & 63,948 & Gestational age group & & & \\
\hline Wednesday & 8,780 & 14.22 & 61,762 & 37-38 weeks & $|8,53|$ & 18.77 & 98,712 \\
\hline Thursday & 8,961 & 14.29 & 62,729 & $39-40$ weeks & 25,628 & 10.56 & 242,645 \\
\hline Friday & 5,212 & 10.73 & 48,555 & $4 I-42$ weeks & 5,419 & 13.34 & 40,632 \\
\hline Saturday & 2,441 & 7.21 & 33,836 & I min Apgar & & & \\
\hline Sunday & 5,797 & 12.40 & 46,737 & Missing & 10 & 16.13 & 62 \\
\hline Semester & & & & $<4$ & $I,|4|$ & 21.61 & 5,281 \\
\hline $200 \mathrm{I}-\mathrm{I}$ & 5,672 & 11.99 & 47,287 & $4-6$ & 2,857 & 14.65 & 19,507 \\
\hline $200 I-2$ & 5,975 & 12.43 & 48,058 & $>6$ & 45,570 & 12.76 & 357,139 \\
\hline $2002-1$ & 5,757 & $|2.5|$ & 46,023 & $5 \mathrm{~min}$ Apgar & & & \\
\hline $2002-2$ & 6,254 & 13.14 & 47,605 & Missing & 10 & 15.38 & 65 \\
\hline $2003-1$ & 6,161 & 13.27 & 46,421 & $<4$ & 163 & 21.73 & 750 \\
\hline $2003-2$ & 6,550 & 13.55 & 48,356 & $4-6$ & 703 & 18.03 & 3,898 \\
\hline 2004-I & 6,319 & 13.24 & 47,734 & $>6$ & 48,702 & $12.9 \mid$ & 377,276 \\
\hline \multirow[t]{7}{*}{$2004-2$} & 6,890 & 13.64 & 50,505 & Respiratory Syndromes & & & \\
\hline & & & & RDS & 480 & 31.27 & 1,535 \\
\hline & & & & Wet lung & 552 & 32.43 & 1,702 \\
\hline & & & & Meconium Aspiration & 510 & 19.23 & 2,652 \\
\hline & & & & Intubation/Ventilation & 959 & 27.88 & 3,440 \\
\hline & & & & Congenital Anomaly & 559 & 16.57 & 3,374 \\
\hline & & & & Admission $\mathbf{N} * / N I C U$ & 9,850 & $|5.3|$ & 64,326 \\
\hline
\end{tabular}

CS: number of cesarean sections carried out; \%: proportion of the cesarean deliveries expressed as a percentage; Total: total number of deliveries with the characteristic under study.

of admission and both the number and proportion of cesarean deliveries, varying respectively between 64,422 and $14.84 \%$ on Monday; and, 33,836 and $7.21 \%$ on Saturday.

\section{Inter-hospital differences in CSR}

We observed considerable and statistically significant inter-hospital differences in CSRs both in the overall analysis and in the longitudinal analysis (Figures 1 and 2). Regarding the period analysis, departures ranged from -65 up to +75 , corresponding to nine "high CSR" and thirteen "low CSR" outlying hospitals with CSRs of respectively $19.3 \%$ and $8.8 \%$ vs $12.9 \%$ in the "average CSR" group. Regarding the trend, hospital-specific departures from the national CSR trend ranged from -6 to +6 and, a difference that did not achieve statistical significance when accounting for multiple comparisons. For instance, the departure, of hospital ID 36 amounted to +6 (Bonferroni-corrected $95 \%$ CI: -2 to +14 ), corresponding to a p-value of 0.01245 which does not reach the Bonferroni-corrected significance level of $0.05 / 107=0.00047$.
Apart from the figures, the feedback to the hospitals included a table, mentioning the departures of period and trend, as well as their Bonferroni-corrected and 95\% CI, the corresponding p-values, and an aid to the interpretation. Regarding the first ten hospitals we provide an example of this feedback in Table 3.

\section{National CSR and its determinants}

To assess the evolution of the CSR, we fitted a multivariable GEE model, accounting for maternal age, wherein evolution over time of the CSR was fitted as a linear trend. Starting from the first semester of 2001 we found a national increasing trend of CS of about $2 \%$ by semester (Table 4, section a). To assess the determinants as available in our data set, a second multivariable GEE was fitted, thereby accounting for time and maternal age as covariates, and determinants listed in table 4. Compared to cesarean risk associated with hospital admission on Sunday, we observed increased CSRs in case of an admission from Monday to Thursday, while the cesarean risk again decreased with admissions on Friday and Saturday. Deliv- 


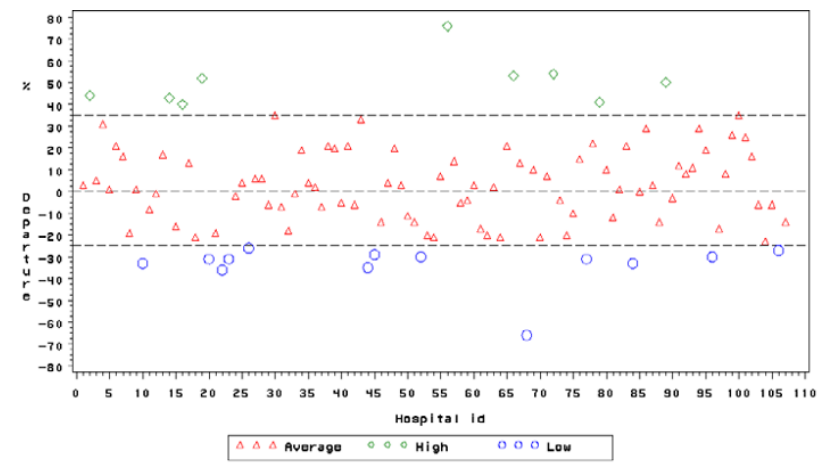

Figure I

Inter-hospital differences in CSR, period. Belgium, 200I-4.

eries at 37-38 weeks and at 41-42 weeks were associated with a significantly increased CSR as compared to 39-40 weeks as well, whereas we were not able to detect a significant association between type of ownership or teaching status of the hospitals and mode of delivery.

\section{Neonatal outcomes}

The bivariate distribution of the neonatal endpoints, according to mode of delivery and CSR group is given in Table 5. With the exception of RDS after a vaginal delivery, all the endpoints were unevenly distributed $(\mathrm{p}<0.01)$ across CSR groups. 1- and 5-minute "Apgar 0-3" scores were more frequent in case of CS and in the "low CSR" group. However, note that the proportion of these scores in the "low CSR" group versus "high CSR" group is smaller in case of a vaginal delivery than after a CS. Regarding RDS and MAS, we observed in the three CSR groups almost identical incidences after a vaginal delivery. The incidences after CS, however, were significantly dissimilar. Indeed, the "average CSR" group seemed to have a smaller RDS incidence, whereas a smaller MAS inci-

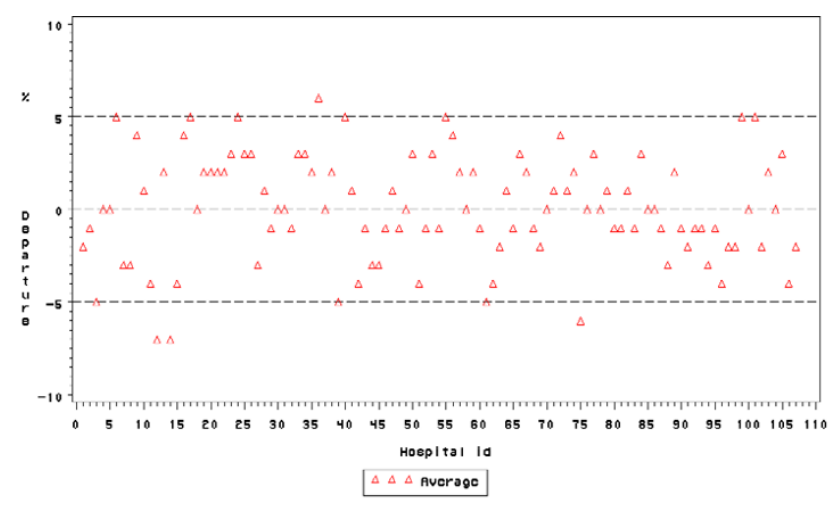

Figure 2

Inter-hospital differences in CSR, trend. Belgium, 200I-4. dence seemed to prevail in the "high CSR" group. TTN seemed to be less problematic in the "high CSR" group, regardless of the mode of delivery. In the "low CSR" group, the need for respiratory assistance seemed more important in both modes of delivery.

The discrepancies regarding the distribution of newborns admitted into a specialized service were striking: the incidences of transfer in the "high CSR" group were five times smaller, regardless of mode of delivery. However, one should be very cautious regarding the variable "admitted into a specialized neonatal service". Indeed, according to this variable, in the "high CSR" group 342 out of 395 newborns with a 1-minute Apgar of 0 to 3 and 1713 out of 1861 newborns with a 1 minute Apgar of 4 to 6 would not have been admitted into a specialized service, which seem hardly plausible figures.

Since the proportional odds assumption was not met, a general logit analysis was carried out to analyze the association between mode of delivery, CSR group and 1minute Apgar and 5-minute Apgar scores in a more formal way. In the 1-minute Apgar analysis, it appeared that there were significantly fewer cases of "Apgar 0-3" scores in the "high" CSR group than in the "average" CSR group, which in turn was significantly less associated with "Apgar 0-3" scores than the "low CSR" group (Table 6). Regarding the "Apgar 4-6" scores we no longer found a significant difference between "average" CSR group and "high" CSR group, whereas the difference between "average CSR" and "low CSR" groups remained significant. Note that cesarean delivery and male gender were negatively associated with the Apgar scores. The 5-minute Apgar analysis essentially gave the same results.

We also investigated the association between mode of delivery, CSR group and respiratory syndromes, certain types of respiration sustaining treatments or the admission of the newborn into a specialized neonatal pediatric service/NICU (see Additional file 5). For all the endpoints considered, CS was significantly associated with an increased occurrence of negative outcomes. For male gender, with the exception of MAS, we observed a similar relationship.

Comparing the "high CSR" and "low CSR" with the "average CSR" group, the "low CSR" group showed an important excess of RDS cases in case of cesarean delivery.

Regarding MAS, and comparing the "low CSR" and "average CSR" groups, we found an excess of MAS cases in the "average CSR" group regardless of mode of delivery. In part, this phenomenon may be due to the adjustment by gestational age, since a significant excess of deliveries at 41 and 42 weeks was observed in the "low CSR" group (RR: 
Table 3: Departure of a hospital's CSR (expressed as a percentage) from the national CSR or trend, Belgium, 200 I-4.

\begin{tabular}{|c|c|c|c|c|c|c|c|c|c|c|c|c|c|c|c|c|c|}
\hline \multirow[t]{2}{*}{ ID $^{\prime}$} & \multicolumn{8}{|c|}{ Period } & \multicolumn{8}{|c|}{ Trend } & \multirow[t]{2}{*}{$\mathbf{I P}^{10}$} \\
\hline & LB_B ${ }^{2}$ & LB_95 3 & $\mathbf{D}(\%)^{4}$ & UB_95 55 & UB_B6 & Cl_957 & $\mathrm{Cl} \_\mathrm{B}^{8}$ & $\mathrm{P}^{9}$ & LB_B2 & LB_95³ & $\mathbf{D}(\%)^{4}$ & UB_95 5 & UB_B6 & Cl_957 & Cl_B8 & $P^{9}$ & \\
\hline I & -18 & -10 & 3 & 16 & 28 & NS & NS & 0.68283 & -11 & -7 & -2 & 4 & 8 & NS & NS & 0.51065 & GM \\
\hline 2 & 24 & 33 & 44 & 56 & 66 & + & + & $<0.00001$ & -8 & -5 & -1 & 3 & 6 & NS & NS & 0.57928 & EA \\
\hline 3 & -20 & -10 & 5 & 23 & 38 & NS & NS & 0.49978 & -16 & -11 & -5 & 2 & 8 & NS & NS & 0.18024 & GM \\
\hline 4 & 9 & 18 & 31 & 44 & 56 & + & + & $<0.00001$ & -8 & -4 & 0 & 5 & 9 & NS & NS & 0.90712 & GM \\
\hline 5 & -20 & -11 & 1 & 15 & 27 & NS & NS & 0.88383 & -10 & -6 & 0 & 5 & 10 & NS & NS & 0.93539 & GM \\
\hline 6 & 9 & 14 & 21 & 29 & 35 & + & + & $<0.00001$ & 0 & 2 & 5 & 8 & 10 & + & NS & 0.00045 & GM \\
\hline 7 & 0 & 7 & 16 & 26 & 35 & + & NS & $0.0006 \mathrm{I}$ & -9 & -7 & -3 & 1 & 4 & NS & NS & 0.11081 & GM \\
\hline 8 & -32 & -26 & -19 & -11 & -5 & - & - & $<0.00001$ & -10 & -7 & -3 & 1 & 4 & NS & NS & 0.10727 & GM \\
\hline 9 & -12 & -7 & 1 & 10 & 17 & NS & NS & 0.75745 & -2 & 1 & 4 & 8 & II & + & NS & 0.01709 & GM \\
\hline 10 & -45 & -40 & -33 & -26 & -19 & - & - & $<0.00001$ & -7 & -3 & $\mathbf{I}$ & 6 & 9 & NS & NS & 0.67442 & EA \\
\hline
\end{tabular}

I ID: Anonymous hospital identifier;

2 LB_B: Lower bound of the Bonferroni confidence interval;

3 LB_95: Lower bound of the $95 \%$ confidence interval;

${ }^{4} \mathrm{D}$ : departure of a hospital's CSR compared with the national CSR/national trend;

5 UB_95: Upper bound of the $95 \%$ confidence interval;

6 UB_B: Upper bound of the Bonferroni confidence interval;

7 Cl 95 : +: a $95 \% \mathrm{Cl}$ suggests a significantly higher hospital's rate/trend compared with the national rate/trend,

-: a $95 \% \mathrm{Cl}$ suggests a significantly lower hospital's rate/trend compared with the national rate/trend,

NS: a $95 \% \mathrm{Cl}$ does not suggest a significant departure of the hospital's rate/trend compared with the national rate/trend.

${ }^{8} \mathrm{Cl} \_\mathrm{B}:+:$ a Bonferroni-corrected $\mathrm{Cl}$ strongly suggests a significantly higher hospital's rate/trend compared with the national rate/trend,

$\therefore$ : a Bonferroni-corrected $\mathrm{Cl}$ strongly suggests a significantly lower hospital's rate/trend compared with the national rate/trend,

NS: a Bonferroni-corrected $\mathrm{Cl}$ does not suggest a significant departure of the hospital's rate/trend compared with the national rate/trend.

$9 \mathrm{P}$ value: Probability of observing departures such as these assuming the null hypothesis of no departure is true.

IOIP: Interpretation: EA: External audit and general measures recommended; GM: General measures recommended.

1.09; 95\% CI $[1.07 ; 1.12])$. By contrast in case of a CS we observed an important excess of cases in the "low CSR" group.

Respiratory support seemed more often needed in the "low CSR" group (OR: 1.27 ; 95\% CI [1.14; 1.43]). Neonatal admission into a specialized service seemed inversely associated with the "high CSR" (OR: $0.11 ; 95 \%$ CI [0.10;0. 12]) and "low CSR" (OR: 0.86; 95\% CI [0.84;0. 89]) groups, especially in case of a vaginal delivery. But as afore-mentioned one should be very cautious when interpreting this endpoint.

Deliveries at 37-38 weeks and at 41-42 weeks were associated with an excess of all the considered endpoints. Comparing the CSR groups regarding the ratio of CS carried out at that gestational age over the total number of CS, we found $40.1 \%$ in the "high CSR" group versus $24.2 \%$ and $37.2 \%$ respectively in the "low CSR" and "average CSR" groups.

The relationship between gestational age and MAS was a peculiar one in the sense that it was significantly negative at a gestational age of 37-38 weeks and significantly positive at a gestational age of 41-42 weeks.

The results of our analyses excluding cases of congenital anomaly were essentially the same (see Additional file 6).

\section{Discussion \\ Main findings}

Our results suggested the existence of sizeable and nationwide inter-hospital variations in CSRs in low-risk deliveries. They rested on a very conservative analysis and interpretational approach, consisting both in defining a zone of non-interpretation and in the use of considerable threshold values before a departure from the national rate or trend was labeled important and statistically significant. We adjusted for multiple simultaneous comparisons and for presence of correlation within the data[31,34], and provided degrees of evidence regarding the observed departure of a hospital, as well as an interpretational aid., thereby avoiding false alerts and reassurance, and allowing distinction between real differences and artefacts [36].

We observed an evolution over time of the CSR, which was best summarized by a national upward trend of $2 \%$ by semester. We observed that obstetrical intervention drastically pervaded childbirth as is reflected by the geographical and hospital-related distributions of CSR, and the distribution of number and mode of deliveries by admission day [37]. Structural issues (nurse staffing, availability of physicians and anesthesiology), not registered in the MCD, may also have intervened in the decision towards elective cesarean section [38]. 
Table 4: CSR evolution and determinants. Belgium 200I-4.

\begin{tabular}{|c|c|c|}
\hline & OR & $\mathbf{P}$ \\
\hline \multicolumn{3}{|l|}{ a) National trend adjusted for age group } \\
\hline Semestrial trend (basis Ist semester 200I) & $1.02(1.02 ; 1.02)$ & $<0.01$ \\
\hline \multicolumn{3}{|l|}{ Age group } \\
\hline $20-24$ years vs $<20$ years & $1.11(1.11 ; 1.11)$ & $<0.01$ \\
\hline $25-29$ years vs $<20$ years & $1.30(1.30 ; 1.30)$ & $<0.01$ \\
\hline $30-34$ years vs $<20$ years & $1.53(1.53 ; 1.53)$ & $<0.01$ \\
\hline $35-39$ years vs $<20$ years & $1.86(1.86 ; 1.86)$ & $<0.01$ \\
\hline 40 years + vs $<20$ years & $2.4 I(2.4 I ; 2.4 I)$ & $<0.01$ \\
\hline \multicolumn{3}{|l|}{ b) National trend of CSR and determinants } \\
\hline Semestrial trend (basis Ist semester 200I) & $1.02(1.01 ; 1.02)$ & $<0.01$ \\
\hline \multicolumn{3}{|l|}{ Age group } \\
\hline $20-24$ years vs $<20$ years & $1.12(1.09 ; 1.22)$ & 0.02 \\
\hline $25-29$ years vs $<20$ years & $1.31(1.20 ; 1.43)$ & $<0.01$ \\
\hline $30-34$ years vs $<20$ years & $1.55(1.42 ; 1.69)$ & $<0.01$ \\
\hline $35-39$ years vs $<20$ years & $1.89(1.73 ; 2.07)$ & $<0.01$ \\
\hline 40 years + vs $<20$ years & $2.45(2.21 ; 2.7 I)$ & $<0.01$ \\
\hline \multicolumn{3}{|l|}{ Gestational age } \\
\hline $37-38$ weeks vs $39-40$ weeks & $1.93(1.87 ; 2.00)$ & $<0.01$ \\
\hline $4 \mid-42$ weeks vs $39-40$ weeks & $1.31(1.26 ; 1.36)$ & $<0.01$ \\
\hline \multicolumn{3}{|l|}{ Residence } \\
\hline Antwerp vs National & $1.00(0.94 ; 1.05)$ & 0.73 \\
\hline Brussels vs National & $0.89(0.84 ; 0.94)$ & $<0.01$ \\
\hline Brabant $(F)$ vs National & $0.97(0.91 ; 1.05)$ & 0.29 \\
\hline Brabant (W) vs National & $0.82(0.75 ; 0.89)$ & $<0.01$ \\
\hline West Flanders vs National & $1.10(1.02 ; 1.18)$ & 0.01 \\
\hline East Flanders vs National & $1.06(1.00 ; 1.13)$ & $<0.01$ \\
\hline Hainaut vs National & $0.94(0.88 ; 1.00)$ & $<0.01$ \\
\hline Liège vs National & $1.34(1.25 ; 1.44)$ & $<0.01$ \\
\hline Limburg vs National & $1.24(1.14 ; 1.34)$ & $<0.01$ \\
\hline Luxembourg vs National & $1.01(0.86 ; 1.18)$ & 0.92 \\
\hline Namur vs National & $0.83(0.77 ; 0.90)$ & $<0.01$ \\
\hline Abroad vs National & $0.93(0.79 ; 1.09)$ & 0.20 \\
\hline \multicolumn{3}{|l|}{ Admission day } \\
\hline Monday vs Sunday & $1.22(1.15 ; 1.29)$ & $<0.01$ \\
\hline Tuesday vs Sunday & $1.13(1.06 ; 1.19)$ & $<0.01$ \\
\hline Wednesday vs Sunday & $1.17(1.10 ; 1.23)$ & $<0.01$ \\
\hline Thursday vs Sunday & $1.17(1.11 ; 1.24)$ & $<0.01$ \\
\hline Friday vs Sunday & $0.85(0.80 ; 0.90)$ & $<0.01$ \\
\hline Saturday vs Sunday & $0.55(0.52 ; 0.59)$ & $<0.01$ \\
\hline
\end{tabular}

OR: odds ratio; () 95\% confidence interval;

\section{Main limitations of the study}

Limitations in completeness and accuracy are intrinsic to vital-statistics and administrative data [22,39] Our laborinduction, epidural anesthesia and history of a previous cesarean data are incomplete, and we observed a possible over-registration of hypertension and diabetes as well (Table 1). The miscoding of these conditions may induce serious flaws in the inter-hospital comparison. Indeed, each of them is related with higher CSRs and may reflect differences in medical or coding practices across hospitals. Therefore, given the magnitude both of the occurrence of these conditions and of the miscoding, we omitted them in the definition of our study population, whereas we used the term screening for inter-hospital differences, which should be completed by external or internal audits. Owing to the very nature of our data, we were unable to formally distinguish between primary elective and repeat cesareans. This can be viewed as another limitation, and, while further analyses of the primary elective cesareans are of major interest as they are the first starting point to contain rising CSRs, the joint analysis is of use for the research question central in this work. Consequently, to avoid flawed inter-hospital comparisons and to improve the effectiveness of the CSR as a quality indicator, multi-fac- 
Table 5: Neonatal endpoints according to mode of delivery and CSR group. Belgium 200I-4.

\begin{tabular}{|c|c|c|c|c|c|c|c|c|c|}
\hline & \multicolumn{9}{|c|}{ CSR groups } \\
\hline & & High & (\%) & Average & (\%) & Low & (\%) & Total & $\mathbf{P}$ \\
\hline \multirow[t]{8}{*}{ I min Apgar } & Vaginal & & & & & & & & \\
\hline & $<4$ & 299 & 1.05 & 3,169 & 1.22 & 672 & 1.52 & 4,140 & $<0.01$ \\
\hline & $4-6$ & 1,512 & 5.31 & 12,857 & 4.95 & $2,28 I$ & 5.16 & 16,650 & \\
\hline & $>6$ & 26,680 & 93.64 & 243,671 & 93.83 & 41,218 & 93.31 & 311,569 & \\
\hline & CS & & & & & & & & \\
\hline & $<4$ & 96 & 1.41 & 918 & 2.38 & 127 & 2.98 & $1,|4|$ & $<0.01$ \\
\hline & $4-6$ & 349 & 5.14 & 2,223 & 5.77 & 285 & 6.68 & 2,857 & \\
\hline & $>6$ & 6,351 & 93.45 & 35,366 & 91.84 & 3,853 & 90.34 & 45,570 & \\
\hline \multirow[t]{8}{*}{5 min Apgar } & Vaginal & & & & & & & & \\
\hline & $<4$ & 32 & 0.11 & 478 & 0.18 & 77 & 0.17 & 587 & $<0.01$ \\
\hline & $4-6$ & 180 & 0.63 & 2,533 & 0.98 & 482 & 1.09 & 3195 & \\
\hline & $>6$ & 28,279 & 99.26 & 256,686 & 98.84 & 43,609 & 98.73 & 328,574 & \\
\hline & CS & & & & & & & & \\
\hline & $<4$ & 11 & 0.16 & 135 & 0.35 & 17 & 0.40 & 163 & $<0.01$ \\
\hline & $4-6$ & 51 & 0.75 & 564 & 1.46 & 88 & 2.06 & 703 & \\
\hline & $>6$ & 6,734 & 99.09 & 37,808 & 98.18 & 4,160 & 97.54 & 48,702 & \\
\hline \multirow[t]{6}{*}{ RDS } & Vaginal & & & & & & & & \\
\hline & Absent & 28,405 & 99.68 & 258,913 & 99.69 & 44,038 & 99.66 & 331,356 & 0.73 \\
\hline & Present & 90 & 0.32 & 816 & 0.31 & 149 & 0.34 & I,055 & \\
\hline & CS & & & & & & & & \\
\hline & Absent & 6,718 & 98.84 & 38,174 & 99.12 & 4,206 & 98.57 & 49,098 & $<0.01$ \\
\hline & Present & 79 & 1.16 & 340 & 0.88 & 61 & 1.43 & 480 & \\
\hline \multirow[t]{6}{*}{ MAS } & Vaginal & & & & & & & & \\
\hline & Absent & 28,331 & 99.42 & 257,974 & 99.32 & 43,964 & 99.50 & 330,269 & $<0.01$ \\
\hline & Present & 164 & 0.58 & I,755 & 0.68 & 223 & 0.50 & 2,142 & \\
\hline & CS & & & & & & & & \\
\hline & Absent & 6,744 & 99.22 & 38,116 & 98.97 & 4,208 & 98.62 & 49,068 & $<0.01$ \\
\hline & Present & 53 & 0.78 & 398 & 1.03 & 59 & 1.38 & 510 & \\
\hline \multirow[t]{6}{*}{ TTN } & Vaginal & & & & & & & & \\
\hline & Absent & 28,425 & 99.75 & 258,814 & 99.65 & 44,022 & 99.63 & 331,261 & $<0.01$ \\
\hline & Present & 70 & 0.25 & 915 & 0.35 & 165 & 0.37 & 1,150 & \\
\hline & CS & & & & & & & & \\
\hline & Absent & 6,740 & 99.16 & 38,082 & 98.88 & 4,204 & 98.52 & 49,026 & $<0.01$ \\
\hline & Present & 57 & 0.84 & 432 & 1.12 & 63 & 1.48 & 552 & \\
\hline \multirow[t]{6}{*}{ Intubation/Ventilation } & Vaginal & & & & & & & & \\
\hline & Absent & 28,295 & 99.30 & 257,854 & 99.28 & 43,781 & 99.08 & 329,930 & $<0.01$ \\
\hline & Present & 200 & 0.70 & 1,875 & 0.72 & 406 & 0.92 & 2,481 & \\
\hline & CS & & & & & & & & \\
\hline & Absent & 6,670 & 98.13 & 37,804 & 98.16 & 4,145 & 97.14 & 48,619 & $<0.01$ \\
\hline & Present & 127 & 1.87 & 710 & 1.84 & 122 & 2.86 & 959 & \\
\hline \multirow[t]{6}{*}{ Admission to specialized neonatal service } & Vaginal & & & & & & & & \\
\hline & Absent & 27,818 & 97.62 & 212,951 & 81.99 & 37,166 & 84.11 & 277,935 & $<0.01$ \\
\hline & Present & 677 & 2.38 & 46,778 & 18.01 & 7,021 & 15.89 & 54,476 & \\
\hline & CS & & & & & & & & \\
\hline & Absent & 6,459 & 95.03 & 29,950 & 77.76 & 3,319 & 77.78 & 39,728 & $<0.01$ \\
\hline & Present & 338 & 4.97 & 8,564 & 22.24 & 948 & 22.22 & 9,850 & \\
\hline
\end{tabular}

(\%): Column percentage

eted actions such as dissemination of the present results in the hospitals, the adoption of explicitly to-filled-out items, quality control of the data and audits are required.

Also our definition of a low-risk group, building on the definition from the AHRQ[1], which includes the basic triad of "mothers with singleton, full-term ( $>37$ weeks) births involving a vertex presentation[21]," may have been incomplete. Kabir et al. for instance used more elaborated selection criteria, based on ICD-9CM codes[40], including diabetes, hypertensive disorders, placenta previa and certain congenital anomalies. Although the medical necessity of systematically carrying out a CS in case of diabetes without macrosomia [41] and hypertensive dis- 
Table 6: Association of CSR group, mode of delivery and I-minute or 5-minute Apgar scores, adjusted for gender, age class and semester. Belgium, 200 I-4.

\begin{tabular}{|c|c|c|c|}
\hline & Response Variable & OR & $\mathbf{P}$ \\
\hline \multicolumn{4}{|l|}{ a) I minute Apgar } \\
\hline \multirow[t]{2}{*}{ Male vs Female } & Apgar 0-3 & $1.32(1.25 ; 1.40)$ & $<0.01$ \\
\hline & Apgar 4-6 & $1.22(1.19 ; 1.26)$ & $<0.01$ \\
\hline \multirow[t]{2}{*}{ CS vs VD } & Apgar 0-3 & $1.76(1.59 ; 1.95)$ & $<0.01$ \\
\hline & Apgar 4-6 & $1.17(1.10 ; 1.24)$ & $<0.01$ \\
\hline \multirow[t]{2}{*}{ CSR group: High vs Low } & Apgar 0-3 & $0.56(0.48 ; 0.65)$ & $<0.01$ \\
\hline & Apgar 4-6 & $0.87(0.80 ; 0.95)$ & $<0.01$ \\
\hline \multirow[t]{2}{*}{ CSR group: High vs Average } & Apgar 0-3 & $0.7 \mathrm{I}(0.48 ; 0.80)$ & $<0.01$ \\
\hline & Apgar 4-6 & 0.97 (0.91; 1.03) & 0.33 \\
\hline \multirow[t]{2}{*}{ CSR group: Low vs Average } & Apgar 0-3 & $1.27(1.14 ; 1.40)$ & $<0.01$ \\
\hline & Apgar 4-6 & $1.12(1.04 ; 1.19)$ & $<0.01$ \\
\hline \multirow[t]{2}{*}{ Average and CS vs High and VD } & Apgar 0-3 & $1.22(1.08 ; 1.37)$ & 0.02 \\
\hline & Apgar 4-6 & $1.11(1.04 ; 1.18)$ & $<0.01$ \\
\hline \multirow[t]{2}{*}{ Average and CS vs Low and VD } & Apgar 0-3 & $0.99(0.90 ; 1.10)$ & 0.88 \\
\hline & Apgar 4-6 & $0.94(0.88 ; 1.01)$ & 0.08 \\
\hline \multirow[t]{2}{*}{ High and CS vs Low and VD } & Apgar 0-3 & $0.82(0.70 ; 0.95)$ & 0.02 \\
\hline & Apgar 4-6 & $0.85(0.78 ; 0.93)$ & $<0.01$ \\
\hline \multicolumn{4}{|l|}{ b) 5 minute Apgar } \\
\hline \multirow[t]{2}{*}{ Male vs Female } & Apgar 0-3 & $1.29(1.12 ; 1.49)$ & $<0.01$ \\
\hline & Apgar 4-6 & $1.31(1.23 ; 1.40)$ & $<0.01$ \\
\hline \multirow[t]{2}{*}{ CS vs VD } & Apgar 0-3 & $1.84(1.37 ; 2.47)$ & $<0.01$ \\
\hline & Apgar 4-6 & $1.52(1.33 ; 1.74)$ & $<0.01$ \\
\hline \multirow[t]{2}{*}{ CSR group: High vs Low } & Apgar 0-3 & $0.5 \mathrm{I}(0.33 ; 0.79)$ & $<0.01$ \\
\hline & Apgar 4-6 & $0.45(0.37 ; 0.55)$ & $<0.01$ \\
\hline \multirow[t]{2}{*}{ CSR group: High vs Average } & Apgar 0-3 & $0.53(0.37 ; 0.76)$ & $<0.01$ \\
\hline & Apgar 4-6 & $0.57(0.49 ; 0.68)$ & $<0.01$ \\
\hline \multirow[t]{2}{*}{ CSR group: Low vs Average } & Apgar 0-3 & $1.04(0.79 ; 1.38)$ & 0.78 \\
\hline & Apgar 4-6 & $1.27(1.12 ; 1.43)$ & $<0.01$ \\
\hline \multirow[t]{2}{*}{ Average and CS vs High and VD } & Apgar 0-3 & $1.15(0.80 ; 1.64)$ & 0.45 \\
\hline & Apgar 4-6 & $1.13(0.96 ; 1.33)$ & 0.15 \\
\hline \multirow[t]{2}{*}{ Average and CS vs Low and VD } & Apgar 0-3 & $0.91(0.69 ; 1.21)$ & 0.51 \\
\hline & Apgar 4-6 & $0.89(0.78 ; 1.00)$ & 0.06 \\
\hline \multirow[t]{2}{*}{ High and CS vs Low and VD } & Apgar 0-3 & $0.79(0.5 \mathrm{I} ; \mathrm{I} .22)$ & 0.29 \\
\hline & Apgar 4-6 & $0.79(0.65 ; 0.96)$ & 0.02 \\
\hline
\end{tabular}

OR: odds ratio; () 95\% Cl.

CS: cesarean section. VD: vaginal delivery.

orders (except some cases of eclampsia with acute fetal distress persisting beyond 10-15 minutes) [42] has not yet univocally been established, current practices are associated with higher caesarean rates. Conversely, mothers suffering from pathologies such as placenta previa and congenital anomalies may be considered at risk of rightly undergoing a CS.

Due to weak case identification from administrative data $[17,36]$, we adopted an intermediate position to define our study population. Yet, it may be acknowledged that applying our criteria to our source population instead of the basic triads criteria would have resulted in a further $12 \%$ risk reduction.

A further shortcoming of our study is the absence of maternal endpoints. Although severe under-registration has been observed in several countries in Europe [43], the maternal mortality rate may be useful in inter-country comparisons, but the low incidence of maternal deaths, 8 cases in our study population out of 12 cases in the population of live born infants, prevent inter-hospital comparisons [43]. Maternal morbidity, the other maternal endpoint has not yet been defined clearly, though probably a very useful indicator of obstetric care [43]. Conditions with permanent disability of the mother such as infertility, vaginal fistulae are exceptional in Europe [43]. "Near misses" or "life-threatening events" and risks of pregnancy and childbirth-related injuries leading to urinary and fecal incontinence are considered as possible indicators for maternal morbidity, which are to be made operational in useful indicators [43]. However, these indicators, when based on administrative data, are akin to patient safety indicators type and may share its limita- 
tions, i.e., although they are appropriate for internal quality improvement efforts, the validity of their use for comparative inter-hospital purposes is still to be established [44].

Finally, part of the limitations of administrative data may be due to the basic tension which exists between using the same data for reimbursement and for measuring quality. "When the use is reimbursement, there is a tendency to perform coding quickly and to maximize the coding of complications and co-morbidities. When the use is to assess quality, however, it is important for coders to have a complete record and to restrict diagnosis coding to conditions that affect patient care [45]." For instance, hypertension and diabetes may intervene in the algorithm used to determine the case mix of an admission and thus be rewarding in financial terms, whereas this may not be the case for labor induction, epidural anesthesia and history of a previous cesarean.

\section{Main strengths}

The comparison of the data regarding selected variables in our study population and the data from other sources, presented in Table 1, showed a good match in terms of completeness and accuracy. Research has shown that a CS is almost always correctly classified [39]. An analysis based on a limited number of variables with known reliability may achieve an inter-hospital comparison, reasonably similar to a comparison based on medical record data [46].

\section{Neonatal endpoints}

We did not include neonatal mortality as an endpoint because it is dependent on neonatal care, which is outside the scope of this study, and further because neonatal mortality is both a rare phenomenon and, due to the mode of registration in Belgium, cannot be linked to the type of delivery in case of transfer to another hospital.

Information on Apgar scores, in contrast, is rarely missing: $0.39 \%$ in an important Swedish study [47] and even less in ours. For the time being, we lack undisputed and countrywide accessible alternatives $[47,48]$. In addition, it is doubtful whether a similar degree of completeness is present regarding the other neonatal endpoints. Since we excluded multiple births, cases of prematurity, IUGR and malpresentation (including breech) $[29,47,49]$ from our study, part of the risk factors for respiratory distress have been avoided. Unfortunately we were not able to take into account other sources of less good Apgar scores [50].

The association of high CSRs with less 1-minute "Apgar 03 " scores seems in accordance with CS performed for fetal distress and to plead in favor of this group. However, SESrelated confounding may have played a role in this rela- tionship [50]. In this group we observed a relative excess of these scores after a vaginal delivery, whereas one would rather have expected an excess of such scores after a CS. This finding may indicate a problem of over-use, especially in this group. More generally indeed, 45,104 newborns, not suffering from congenital anomalies and having a 1-minute Apgar > 6, were delivered by CS. Since evidence from Flanders, the Northern part of Belgium, shows that about $8 \%$ of the women delivering during the study period had a history of a previous CS[51], one may conclude that at least an important part of them has been delivered by a CS not carried out for strictly medical reasons.

On the other hand, 574 newborns without congenital anomalies and with 5-minute "Apgar 0-3" scores were vaginally delivered. Similarly 3,114 of such newborns with 5-minute "Apgar 4-6" scores were delivered vaginally. Both groups might have benefited from a CS, indicating a possible under-use of this procedure. Indeed, 5minute Apgar scores are still considered a valid predictor of neonatal mortality [28].

As in the diagnostic area and in peer review [52], arguably Apgar scores are subject to inter-observer variability [49]. But we may have removed some of it through the categorization of the Apgar scores in agreed on classes.

The results regarding other neonatal endpoints were not univocal and we were anxious about the completeness of our data, given the open-ended question type of registering. Our aforementioned finding in the "high CSR" group of an important proportion of newborns with 5-minute Apgar scores $<7$ and not admitted in a specialized neonatal service illustrates this incompleteness. Literature data regarding MAS, RDS and TTN showing both similarities and important dissimilarities regarding incidence of the pathologies and their association with Apgar scores or mode of delivery are further arguments in favor of this hypothesis [25,53].

Apart from these concerns, in most of these endpoints CS seemed to be associated with less desirable neonatal outcomes and "low CSR" hospitals seemed to perform less well, which is consistent with the findings of another study [38].

Some findings did not favor the "high CSR" group neither. Indeed, deliveries at 37-38 weeks were associated with both an excess of cesarean deliveries and of all the considered endpoints. This finding is consistent with the literature stating that elective CS should be carried out at 39-40 weeks of gestational age rather than at 37-38 weeks, often the case in Belgium. Indeed, at the latter gestational age, before the onset of spontaneous labor, respiratory prob- 
lems more commonly occur [9]. Comparing the CSR groups regarding the ratio of cesarean deliveries carried out at that gestational age over the total number of CS, we found $40.1 \%$ in the "high CSR" group versus $24.2 \%$ and $37.2 \%$ respectively in the "low CSR" and "average CSR" groups. Of course, in the multiple analyses the fact of having undergone a CS comes on top of the often adverse effects from the other endpoints and determinants under study. These considerations suggest that the "average CSR" group might be the more adequate benchmark.

\section{Conclusion}

Despite our efforts to reduce the limitations typical of administrative data, our results are arguably a useful "screening," which may trigger initiatives for quality-ofcare improvement in the hospitals, rather than providing definitive statements at this stage [54]. Indeed, the interhospital differences in CSR, the national CS upward trend, the indications of over-use and under-use, the geographically different obstetric patterns and the admission dayrelated concentration of deliveries, whether or not by CS, are such that an explanation is overdue.

\section{Disclaimer}

The authors of this article are responsible for its contents. No statement in this article should be construed as an official position of the Federal Service of Health, Food Chain Safety and Environment, Directorate-General for the Organization of Health Care Establishments.

\section{Competing interests}

The author(s) declare that they have no competing interests.

\section{Authors' contributions}

WA conceived of the study, drafted the manuscript, and participated in the design of the study and in the statistical analysis. FW was responsible for the data management and participated in the statistical analysis. GM supervised the statistical analysis and participated in the design of the study. PVR participated in the design of the study (neonatal endpoints). HV participated in the design of the study (obstetrical endpoints). JMF participated in the design of the study (obstetrical endpoints). All authors made important contributions to the interpretation of data and the redaction of the final manuscript, and approved it.

\section{Additional material}

\section{Additional file 1}

annex. Aid to the interpretation: algorithm to classify the hospitals according to their departure from the national mean and trend.

Click here for file

[http://www.biomedcentral.com/content/supplementary/1472-

6963-8-3-S1.doc]

\section{Additional file 2}

Major congenital anomalies. ICD-9-CM codes regarding major congenital anomalies potentially related to birth asphyxia.

Click here for file

[http://www.biomedcentral.com/content/supplementary/14726963-8-3-S2.doc]

\section{Additional file 3}

Table 1 completeness and accuracy extended. An exhaustive version of table 1 covering now the whole period of 2001-4 instead of the years 2002 and 2004.

Click here for file

[http://www.biomedcentral.com/content/supplementary/14726963-8-3-S3.doc]

\section{Additional file 4}

Table 2 characteristics supplementary. Supplementary data are provided regarding month of admission, residence of the mother, and type of hospital (MICU, Teaching, Ownership).

Click here for file

[http://www.biomedcentral.com/content/supplementary/14726963-8-3-S4.doc]

\section{Additional file 5}

Respiratory syndromes and mode of delivery (ano incl). Occurrence of respiratory syndromes, respiratory support, transfer into a specialized service associated with mode of delivery and CSR group, adjusted for gender, maternal age, gestational age and semester of delivery. Cases of congenital anomaly included.

Click here for file

[http://www.biomedcentral.com/content/supplementary/14726963-8-3-S5.doc]

\section{Additional file 6}

Respiratory syndromes and mode of delivery wo anomali. Occurrence of respiratory syndromes, respiratory support, transfer into a specialized service associated with mode of delivery and CSR group, adjusted for gender, maternal age, gestational age and semester of delivery. Cases of congenital anomaly excluded.

Click here for file

[http://www.biomedcentral.com/content/supplementary/14726963-8-3-S6.doc]

\section{Acknowledgements}

The authors thank Mrs Nathalie Terryn for her assistance with the graphs.

\section{References}

I. Cesarean Delivery Rate AHRQ Quality Indicators - Guide to Inpatient Quality Indicators: Quality of Care in Hospitals - Volume, Mortality, and Utilization. Revision 4 edition. 2004, IQI 21:67-69 [http://www.qualityin dicators.ahrq.gov/iqi overview.htm]. Rockvile, MD, Agency for Healthcare Research and Quality

2. Anderson GM: Making sense of rising caesarean section rates. BMJ 2004, 329:696-697.

3. Meikle SF, Steiner CA, Zhang J, Lawrence WL: A national estimate of the elective primary cesarean delivery rate. Obstet Gynecol 2005, 105:751-756.

4. Gregory KD, Korst LM, Gornbein JA, Platt LD: Using administrative data to identify indications for elective primary cesarean delivery. Health Serv Res 2002, 37:1387-140I.

5. Guise JM, McDonagh MS, Hashima J, Kraemer DF, Berlin M, Nygren P, Osterweil P, Krages KP, Helfand M: Vaginal Birth After Cesar- 
ean (VBAC). 2003, AHRQ Publication No. 03-E0 I8:1-526 [http://www.ncbi.nlm.nih.gov/books/bv.fcgi?rid=hstatla.chapter.7/49 ]. Rockville,MD, AHRQ

6. Minkoff $\mathrm{H}$, Chervenak FA: Elective primary cesarean delivery. $\mathrm{N}$ Engl J Med 2003, 348:946-950

7. Wu S, Kocherginsky M, Hibbard JU: Abnormal placentation: twenty-year analysis. Am J Obstet Gynecol 2005, 192:|458-| 46I.

8. National Collaborating Centre for Women's and Children's Health: Caesarean Section. 2004: I I 43 [http://www.nice.org.uk/]. London NWI 4RG, RCOG Press

9. Kolas T, Saugstad OD, Daltveit AK, Nilsen ST, Oian P: Planned cesarean versus planned vaginal delivery at term: Comparison of newborn infant outcomes. Am J Obstet Gynecol 2006.

10. Guihard $\mathrm{P}$, Blondel $\mathrm{B}$ : Trends in risk factors for caesarean sections in France between 198I and 1995: lessons for reducing the rates in the future. BJOG 200I, 108:48-55.

11. Paterson-Brown S: Should doctors perform an elective caesarean section on request? Yes, as long as the woman is fully informed. BMJ 1998, 317:462-463.

12. Gonen R, Tamir A, Degani S: Obstetricians' opinions regarding patient choice in cesarean delivery. Obstet Gynecol 2002, 99:577-580

13. Amu O, Rajendran S, Bolaji II: Should doctors perform an elective caesarean section on request? Maternal choice alone should not determine method of delivery. BM] 1998, 3 I 7:463-465.

14. Zeitlin J, Wildman K, Breart G, Alexander S, Barros H, Blondel B, Buitendijk S, Gissler M, MacFarlane A: Selecting an indicator set for monitoring and evaluating perinatal health in Europe: criteria, methods and results from the PERISTAT project. Eur Obstet Gynecol Reprod Biol 2003, I I I Suppl I:S5-SI 4 .

15. Chaillet N, Dumont A: Evidence-based strategies for reducing cesarean section rates: a meta-analysis. Birth 2007, 34:53-64.

16. Donabedian A: The quality of care. How can it be assessed? JAMA 1988, 260: 1743-1748

17. Schwartz RM, Gagnon DE, Muri JH, Zhao QR, Kellogg R: Administrative data for quality improvement. Pediatrics 1999 I03:291-301.

18. Buitendijk S, Zeitlin J, Cuttini M, Langhoff-Roos J, Bottu J: Indicators of fetal and infant health outcomes. Eur J Obstet Gynecol Reprod Biol 2003, I I I Suppl I:S66-S77.

19. Bekaert A, Martens G, Devlieger H, Amy J]: Perinatal Activities in Flanders, 1 996. Brussels, SPE; 1997: I-62.

20. MacFarlane A, Gissler M, Bolumar F, Rasmussen S: The availability of perinatal health indicators in Europe. Eur J Obstet Gynecol Reprod Biol 2003, I I I Suppl I:SI5-S32.

21. Declercq E, Menacker F, MacDorman M: Maternal risk profiles and the primary cesarean rate in the United States, I9912002. Am J Public Health 2006, 96:867-872.

22. Mark $D H$ : Race and the limits of administrative data. JAMA 200I, 285:337-338

23. Armitage P, Berry G: Multiple Measurements. In Statistical Methods in Medical Research Volume. Third edition. Oxford, Blackwell Science Ltd.; I 994:3 I2-385.

24. Dani C, Reali MF, Bertini G, Wiechmann L, Spagnolo A, Tangucci M, Rubaltelli FF: Risk factors for the development of respiratory distress syndrome and transient tachypnoea in newborn infants. Italian Group of Neonatal Pneumology. Eur Respir 1999, I 4:155-159.

25. Yoder BA, Kirsch EA, Barth WH, Gordon MC: Changing obstetric practices associated with decreasing incidence of meconium aspiration syndrome. Obstet Gynecol 2002, 99:73I-739.

26. Papile LA: The Apgar score in the 2 Ist century. N Engl J Med 200I, 344:519-520.

27. Patel D, Piotrowski ZH, Nelson MR, Sabich R: Effect of a statewide neonatal resuscitation training program on Apgar scores among high-risk neonates in Illinois. Pediatrics 200I, 107:648-655.

28. Moster D, Lie RT, Irgens LM, Bjerkedal T, Markestad T: The association of Apgar score with subsequent death and cerebra palsy: A population-based study in term infants. J Pediatr 200I, 138:798-803.

29. Wu YW, Backstrand KH, Zhao S, Fullerton HJ, Johnston SC: Declining diagnosis of birth asphyxia in California: 1991-2000. Pediatrics 2004, II 4:1584-1590.
30. Verbeke G, Molenberghs G: Linear Mixed Models for Longitudinal Data New York, Springer-verlag.; 2000: I-568.

31. Molenberghs G, Verbeke G: Models for Discrete Longitudinal Data New York, Springer-verlag.; 2005: I-683.

32. Hosmer DW, Lemeshow S: Interpretation of the Fitted Logistic Regression Model. In Applied Logistic Regression Volume 3. 2nd edition. Edited by: Hosmer DW and Lemeshow S. New York, John Wiley \& Sons, INC.; 2000:47-90

33. Zhang J, Yu KF: What's the relative risk? A method of correcting the odds ratio in cohort studies of common outcomes. JAMA 1998, 280:1690-1691.

34. Allison PD: Logit Analysis of Contingency Tables. In Logistic Regression Using the SAS System: Theory and Application. Edited by: Allison PD. Cary, NC, SAS Institute Inc.,; 1999:8I-II0.

35. Agresti A: Multinomial Response Models. In Categorical Dato Analysis New York, John Wiley \&Sons.; 1990:306-346.

36. Powell $A E$, Davies $H T$, Thomson RG: Using routine comparative data to assess the quality of health care: understanding and avoiding common pitfalls. Qual Saf Health Care 2003, I 2: I22-I 28.

37. Johanson R, Newburn M, MacFarlane A: Has the medicalisation of childbirth gone too far? BM/ 2002, 324:892-895.

38. Gould JB, Danielsen B, Korst LM, Phibbs R, Chance K, Main E, Wirtschafter DD, Stevenson DK: Cesarean delivery rates and neonatal morbidity in a low-risk population. Obstet Gynecol 2004, 104:II-19.

39. Lydon-Rochelle M, Holt VL, Easterling TR, Martin DP: Risk of uterine rupture during labor among women with a prior cesarean delivery. $N$ Engl J Med 200I, 345:3-8.

40. Kabir AA, Pridjian G, Steinmann WC, Herrera EA, Khan MM: Racial differences in cesareans: an analysis of U.S. 200 I National Inpatient Sample Data. Obstet Gynecol 2005, 105:710-7|8.

4I. Naylor CD, Sermer M, Chen E, Sykora K: Cesarean delivery in relation to birth weight and gestational glucose tolerance: pathophysiology or practice style? Toronto Trihospital Gestational Diabetes Investigators. JAMA 1996, 275: I I65-II 70.

42. Sibai BM: Diagnosis, prevention, and management of eclampsia. Obstet Gynecol 2005, 105:402-4I0.

43. Alexander S, Wildman K, Zhang W, Langer M, Vutuc C, Lindmark G: Maternal health outcomes in Europe. Eur J Obstet Gynecol Reprod Biol 2003, I I I Suppl I :S78-S87.

44. Zhan C, Miller MR: Administrative data based patient safety research: a critical review. Qual Saf Health Care 2003, I 2 Suppl 2:ii58-ii63.

45. AHRQ: AHRQuality Indicators e-Newsletter: AHRQ Q TIPS: ICD-9-CM Coding Issues. 2005 [http://www.qualityindica tors.ahrq.gov/newsletter/2005-September-AHRQ-QI-Newslet ter.htm].

46. DiGiuseppe DL, Aron DC, Payne SM, Snow RJ, Dierker L, Rosenthal GE: Risk adjusting cesarean delivery rates: a comparison of hospital profiles based on medical record and birth certificate data. Health Serv Res 200I, 36:959-977.

47. Thorngren-Jerneck K, Herbst A: Low 5-minute Apgar score: a population-based register study of I million term births. Obstet Gynecol 200I, 98:65-70.

48. O'donnell CP, Kamlin CO, Davis PG, Carlin JB, Morley C): Interobserver variability of the 5-minute Apgar score. J Pediatr 2006, I 49:486-489.

49. ACOG Committee Opinion. Number 333, May 2006 (replaces No. 174, July 1996): The Apgar score. Obstet Gynecol 2006, 107:1209-12/2

50. Hemminki E, Malin M, Rahkonen O: Mother's social class and perinatal problems in a low-problem area. Int J Epidemiol 1990 , 19:983-990.

5I. Perinatale Activiteiten in Vlaanderen 2005. Edited by: Cammu H, Martens G, De Coen K, C. VM and Defoort P. Brussel, Studiecentrum Perinatale Epidemiologie; 2006: I-7I.

52. Hayward RA, Hofer TP: Estimating hospital deaths due to medical errors: preventability is in the eye of the reviewer. JAMA 200I, 286:4I5-420.

53. Wiswell TE, Gannon CM, Jacob I Goldsmith L Szyld E, Weiss K, Schutzman D, Cleary GM, Filipov P, Kurlat I, Caballero CL, Abassi S, Sprague D, Oltorf C, Padula M: Delivery room management of the apparently vigorous meconium-stained neonate: results of the multicenter, international collaborative trial. Pediatrics 2000, 105: $1-7$. 
54. lezzoni Ll: Assessing quality using administrative data. Ann Intern Med 1997, 1 27:666-674.

\section{Pre-publication history}

The pre-publication history for this paper can be accessed here:

http://www.biomedcentral.com/1472-6963/8/3/prepub

Publish with Biomed Central and every scientist can read your work free of charge

"BioMed Central will be the most significant development for disseminating the results of biomedical research in our lifetime. " Sir Paul Nurse, Cancer Research UK

Your research papers will be:

- available free of charge to the entire biomedical community

- peer reviewed and published immediately upon acceptance

- cited in PubMed and archived on PubMed Central

- yours - you keep the copyright
BioMedcentral 